\title{
Maxillary nerve block within the pterygopalatine fossa for oral extraction of maxillary cheek teeth in 80 horses
}

\author{
Clarissa Michaela Riederl, Timo Zwick², Klaus Hopster', Karsten Feige ${ }^{l}$ and Astrid Bienert-Zeit ${ }^{7}$ \\ ${ }^{1}$ Clinic for Horses, University of Veterinary Medicine Hannover, Foundation, Hannover, Germany \\ 2 Veterinary Clinic Gessertshausen, Gessertshausen, Germany
}

\begin{abstract}
Summary: Based on the results of previous studies, the maxillary nerve block using the Extraperiorbital Fat Body Insertion (EFBI)-technique should provide anaesthesia of the maxillary cheek teeth with a minimized risk for complications. Clinical investigations were required to approve the practicability of the EFBI-technique performed on a greater number of standing, sedated horses; monitor possible risks and complications in patients; evaluate the analgesic effect achieved by the EFBI-technique; investigate a possible difference of effectiveness using two different volumes of local anaesthetic. Eighty horses were included in this blinded study and divided into two groups either receiving 2 or $4 \mathrm{ml}$ lidocaine / $100 \mathrm{~kg}$ bodyweight for local nerve block. Maxillary cheek tooth extraction was performed thereafter in the standing, sedated horse. The local block using EFBI-technique was easy to perform in all horses and its practicability under clinical conditions was confirmed. A difference of analgesic effects using two different volumes of the local anaesthetic could not be detected. To minimize risks and complications, it is advisable to use the lower dose with $2 \mathrm{ml} / 100 \mathrm{~kg}$ bodyweight lidocaine.
\end{abstract}

Keywords: horse; equine dentistry; local anaesthesia; maxillary nerve block; EFBI-technique, cheek tooth extraction

Citation: Rieder C. M., Zwick T., Hopster K., Feige K., Bienert-Zeit A. (2016) Maxillary nerve block within the pterygopalatine fossa for oral extraction of maxillary cheek teeth in 80 horses. Pferdeheilkunde 32, 587-594

Correspondence: Astrid Bienert-Zeit, Clinic for Horses, University of Veterinary Medicine Hannover, Foundation, Bünteweg 9, 30559 Hannover, Germany; E-mail: Astrid.Bienert@tiho-hannover.de

\section{Introduction}

Extraction of teeth, especially cheek teeth, is a widely performed procedure in the treatment of severe dental and periodontal diseases in the horse (Dixon et al. 2000). Nevertheless, equine dental surgeries are associated with a high rate of complications compared to other surgical procedures (Prichard et al. 1992). Conventional tooth removal techniques (e.g. repulsion, classical buccotomy) usually require general anaesthesia and are often followed by postoperative complications (Dixon et al. 2000). Consequently, exodontia techniques that are performed in the standing, sedated horse have been enhanced and successfully applied over the last years (Tremaine 2007). Local or regional anaesthesia plays an important role in reducing risks and financial costs associated with general anaesthesia and recovery (Bardell et al. 2010). Regional nerve blocks are the key to successfully perform dental extractions in the standing horse in combination with the use of potent sedative and analgesic drugs (Rawlinson 2011).

Local nerve blocks are easy to perform and usually well tolerated by horses. Less sedation is required during dental procedures when local anaesthesia is successfully obtained (Fletcher 2004). Without the use of regional nerve blocks in conscious horses, the successful tooth extraction relies much on the cooperation of calm horses, in conjunction with the use of very high doses of intravenous sedatives and uncomplicated extraction procedures (Rawlinson 2011).

The maxillary nerve block provokes analgesia of the maxillary cheek teeth and paranasal region (Moyer et al. 2011). The maxillary nerve branches from the fifth cranial nerve within the pterygopalatine fossa enters the maxillary canal by passing through the maxillary foramen. Within the maxillary canal alveolar branches are innervating the maxillary cheek teeth and their periodontium (Easley 1996).

Vlaminck and Steenhaut (2001) and Fletcher (2004) suggested anaesthetizing the maxillary nerve caudal from the maxillary foramen; this technique is known as Maxillary Foramen Block. Therefore, a spinal needle is inserted into the pterygopalatine fossa, just ventral to the zygomatic arch until the needle tip contacts the perpendicular plate of palatine bone. The maxillary nerve is blocked with up to $20 \mathrm{ml}$ lidocaine. This technique (designated as Palatine Bone Insertion (PBI)-technique" according to Staszyk et al. [2008]) has a high risk for puncturing blood vessels and nerves. Several complications, such as hematoma, exophthalmos and blindness are described after application of this technique (Bienert et al. 2011). Therefore Staszyk et al. (2008) modified the method. With the Extraperiorbital Fat Body Insertion (EFBI)-technique the needle is inserted less deeply and the local anaesthetic is injected into the extraperiorbital fat body. The study of Staszyk et al. (2008) using cadaveric heads demonstrated that accidental puncturing of relevant anatomical structures is avoided. In this study a volume of $10 \mathrm{ml}$ was as effective as a volume of $20 \mathrm{ml}$ in terms of spreading of the medium and consistent distribution around the maxillary nerve (Staszyk et al. 2008). However, sufficient regional anaesthesia and analgesia using this EFBI-technique could only be assumed by the results of this study.

Therefore evaluation of the EFBI-technique was performed in order to assess effectiveness and risks under clinical conditions. Rieder et al. (2016) confirmed in an experimental trail that the EFBI-technique is feasible. The results of this study indicated that a dose of $2 \mathrm{ml} / 100 \mathrm{~kg}$ BW lidocaine might be sufficient. However, due to deep sedation of their horses, a 
general appraisement for sufficient analgesia of the maxillary cheek teeth with the performed tests was not possible.

Clinical investigations in the context of maxillary cheek tooth extraction would be beneficial to further confirm these results. Hence, the present clinical study with the following aims was designed:

- Evaluating the practicability of the EFBI-technique performed in the standing, sedated horse undergoing a maxillary cheek tooth extraction,

- Evaluating the analgesic effect achieved by the EFBI-technique,

- Evaluating a possible discrepancy of effectiveness using two different volumes of local anaesthetic, Monitoring of possible risks and complications during and after the performance of the local anaesthesia.

\section{Material and Methods}

Animals

Eighty horses (40 geldings, 39 mares, one stallion; 27 different breeds; 5 to 24 years old) were used for this study. All horses were presented to the Veterinary Clinic Gessertshausen for cheek tooth extraction (e. g. due to tooth fracture, periodontitis, open pulp, apical infections).

\section{Study design}

In all 80 horses unilateral maxillary cheek tooth extraction was necessary. First attempt was the removal of the tooth by oral extraction; if this method failed, the tooth was removed by minimally invasive buccotomy or expulsion using a Steinmann-Pin.

The study was designed as a randomized, prospective, blinded, clinical trial. With the help of a consecutively numbered list, horses were divided into two groups of 40 animals. Group 1 achieved $2 \mathrm{ml} / 100 \mathrm{~kg}$ bodyweight of local anaesthetic, Group 2 achieved $4 \mathrm{ml} / 100 \mathrm{~kg}$ bodyweight of local anaesthetic for the local nerve block. A first, non-blinded investigator (A) performed all maxillary nerve blocks under comparable conditions whereas a second, blinded investigator (B) made all study-related measurements.

Baseline measurements of heart and respiratory rate were performed (investigator B) after entering the examination room and before sedation. Thereafter horses were sedated using a combination of detomidine $(0.02-0.04 \mathrm{mg} / \mathrm{kg}$; Domosedan ${ }^{\circledR}$, Pfizer, Berlin, Germany) and butorphanol (0.1 mg/kg; Torbugesic ${ }^{\circledR}$, Fort Dodge, Würselen, Germany).

\section{Nerve block}

The maxillary nerve block was performed using the Extraperiorbital Fat Body Insertion (EFBI)-technique according to recommendations of Staszyk et al. (2008). The puncture site was determined $10 \mathrm{~mm}$ ventral to the zygomatic arch at a transversal plane between the middle third and the caudal third of the eyeball. Insertion was performed at a $90^{\circ}$ angle to the surface of the skin. A $0.9 \times 90 \mathrm{~mm}, 20 \mathrm{G} \times 31 / 2^{\prime \prime}$ spinal needle $\left(\right.$ Neoject $^{\circledR}$, Dispomed Witt oHG, Gelnhausen, Germany) was forwarded through the masseter muscle. After passing the intersection between the masseter muscle and the extraperiorbital fat body, the needle was advanced another centimeter. After ensurance of the correct needle position the lidocaine was injected into the fat body within the pterygopalatine fossa.

Oral extraction started ten minutes after performing the local nerve block. The extraction of the diseased maxillary cheek tooth was performed according to recommendations of Lowder (1999). In cases of complications, e.g. fracturing the diseased tooth with retention of apical fragments, the oral extraction was stopped and expulsion by Steinmann-Pin or minimally invasive buccotomy was performed.

\section{Measurements}

Complications regarding the performance of the nerve block (aspiration of venous blood, occurrence of turgor ventral of the zygomatic arch, dorsal of the eye within the range of the supraorbital fossa and within the range of the palpebra) as well as acceptance of lidocaine injection by the horses (obvious lifting of the head, chewing, tremor of the head, tremor of the head in combination with chewing, stamping with front leg) were recorded.

Before and five minutes after performing the local block, a Schirmer Tear Test was performed on the side of the head the dependent tooth was extracted.

Further, investigator B (blinded) tested pain sensation by using two experimental settings at these time points:

- A mechanical stimulus was produced with a $22 \mathrm{G} \times 1 \frac{1}{4^{\prime \prime}}$, $0.7 \times 30 \mathrm{~mm}$ needle $\left(\right.$ Neoject $^{\circledR}$, Bela-pharm, Langförden, Germany) on the palatale gingiva in the area of the maxillary cheek tooth that had to be extracted. The needle was stung into the gingiva five times with a depth about $1-3 \mathrm{~mm}$.

- A thermal stimulus was set on the occlusal surface of the dependent tooth using cooling spray (Sport Cooling Spray ${ }^{\circledR}$, Henry Schein, Gillingham, UK). A small plastic tube (6 centimeter length) enabled local spraying on the occlusal surface of the dependent tooth for five seconds.

Parameters for defending reactions as headbanging or chewing were scored from 0 to 2 (no reaction [0], chewing [1], headbanging [2]).

Before and during surgery the heart and respiratory rate as well as occurrence, type and number of defense reactions (headbanging, headshaking, stepping forward or backward) and behaviour of the horses were recorded every five minutes.

Degree of sweating was assessed using a scoring system from 0 to 3 (no [0], lightly [1], moderate [2], heavy [3]). Reaction of the pupils was classified in two categories (no reaction [0], mydriasis [1]). Degree of chewing was graded using a scoring system from 0 to 3 (no [0], lightly [1], frequently [2], strong 
and frequently [3]) and amount of vocalization was classified in three categories (groaning [1], neighing [2], snorting [3]).

\section{Follow-up examinations}

Penicillin combined with streptomycin 20.000l.E./kg BW i.m. (Veracin-compositum ${ }^{\circledR}$, Fa. Albrecht, Aulendorf, Germany) and flunixin-meglumine $1.1 \mathrm{mg} / \mathrm{kg} \mathrm{BW}$ i.v. (Paraflunixin ${ }^{\circledR}$, IDT, Rodleben, Germany) were administered to all horses for three to five days. During the first four days after extraction clinical examination was performed daily especially looking for swelling or secondary bleeding of the injection site. The periocular area was monitored regarding blepharospasm, miosis, or swollen palpebrae.

\section{Statistical analysis}

The division of the incidents and complications during the performance of the local nerve block was analyzed for differences between the low and high volume of lidocaine using the Chi-Square-Test. Differences were considered significant for $\mathrm{p}<0.05$.

The frequency distribution of the mild defense reactions that occurred during testing pain sensation was analyzed for differences before and after the local nerve block using the ChiSquare-Test and the Mc-Nemar s-Test.

The scores of each defense reaction and behaviour of every horse during the oral extraction were analysed for differences between the lower and higher volume of lidocaine using the Wilcoxon-paired test and the Chi-Square-Test. Differences were considered significant for $p<0.05$.

\section{Results}

Maxillary nerve block

Procedure and reactions of the horses

In 74 of 80 horses $(92.5 \%)$ the maxillary nerve block was set within the first attempt. In 4 horses (5\%) a nose-twitch was necessary for a safe performance of the local nerve block and in 2 horses $(2.5 \%)$ a repositioning of the spinal needle was necessary.

Sixty-five of the horses (81.3\%) showed no adverse reaction during needle placement or lidocaine injection. The remai- ning 15 horses showed mild to moderate reactions as shown in Figure 1.

Complications during the performance of the nerve block

In 65 horses maxillary nerve block caused no further complication. In the remaining horses (15 out of $80 ; 18.7 \%$ ) following complications occurred during or right after the nerve block:

Blood aspiration in 13 horses, 6 horses of group 1 and 7 horses of group 2. A correct repositioning of the spinal needle was done before injecting lidocaine:

Group 1: six horses: Two horses showed mild chewing during the injection

Group 2: seven horses: Two horses showed mild chewing during the injection. After the nerve block another three horses developed an articulate swelling dorsal the eye within the area of the supraorbital fossa. These three horses did not show any signs of pain palpating the swollen area. After the surgical intervention was finished they got a cold and wet compression bandage over the swollen area for the next 24 hours. In all cases the swelling disappeared within three days.

In two experiments horses developed a diffuse turgor:

Group 1: One horse ventral of the zygomatic arch

Group 2: One horse dorsal to the eye within the range of the upper palpebrae a few minutes after the nerve block.

\section{Lacrimation rate}

Schirmer Tear Test was performed in 51 horses (63.7\%). There were no significant differences between the lacrimation rate before and after local anaesthesia although there was a trend for a decrease of lacrimation rate after local anaesthesia (Figure 2).

\section{Reaction of the pupil}

In 21 horses (26.3\%) a moderate mydriasis occurred after the nerve block. In horses of group 1 (10 of 21) mydriasis lasted for a mean time of 17 minutes whereas in horses of group 2 (11 of 21) mydriasis lasted for more than 21 minutes. In 2 horses the pupil was normal sized again before starting dental extraction and in the remaining 19 horses pupil was normal sized at the end of extraction procedure.

\section{Incidents during nerve block performance}

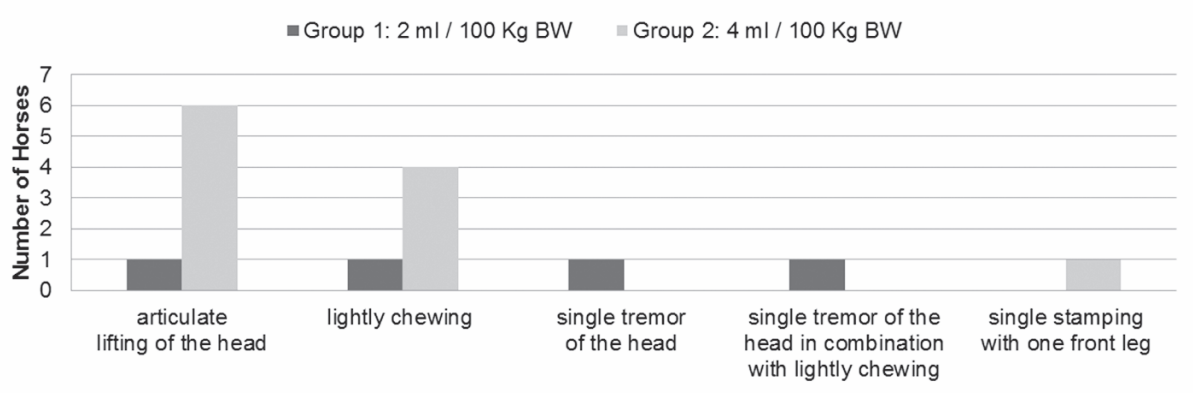

Fig. 1 Incidents during nerve block performance of 80 sedated horses (group 1: $2 \mathrm{ml} / 100 \mathrm{~kg}$ BW lidocaine and group 2: $4 \mathrm{ml} / 100 \mathrm{~kg}$ BW lidocaine)

Unerwünschte Vorfälle während der Durchführung der Leitungsanästhesie an 80 sedierten Pferden (Gruppe 1: $2 \mathrm{ml}$ Lidocain/100 kg Körpergewicht und Gruppe 2: $4 \mathrm{~m} /$ Lidocain/100 kg Körpergewicht) 
Fig. 2 Results of Schirmer Tear Test $(\mathrm{n}=51)$ in $\mathrm{mm} / \mathrm{min}$ before and after maxillary nerve block (above); lacrimation rate comparative after maxillary nerve block (below) Ergebnisse des Schirmer-Tränen-Tests $\quad(n=51)$ in $\mathrm{mm} /$ Minute vor und nach der Lokalanästhesie des $\mathrm{N}$. maxillaris (oben); Lakrimationsrate vergleichend nach der Lokalanästhesie des N. maxillaris (unten)

\section{Results of Schirmer Tear Test}

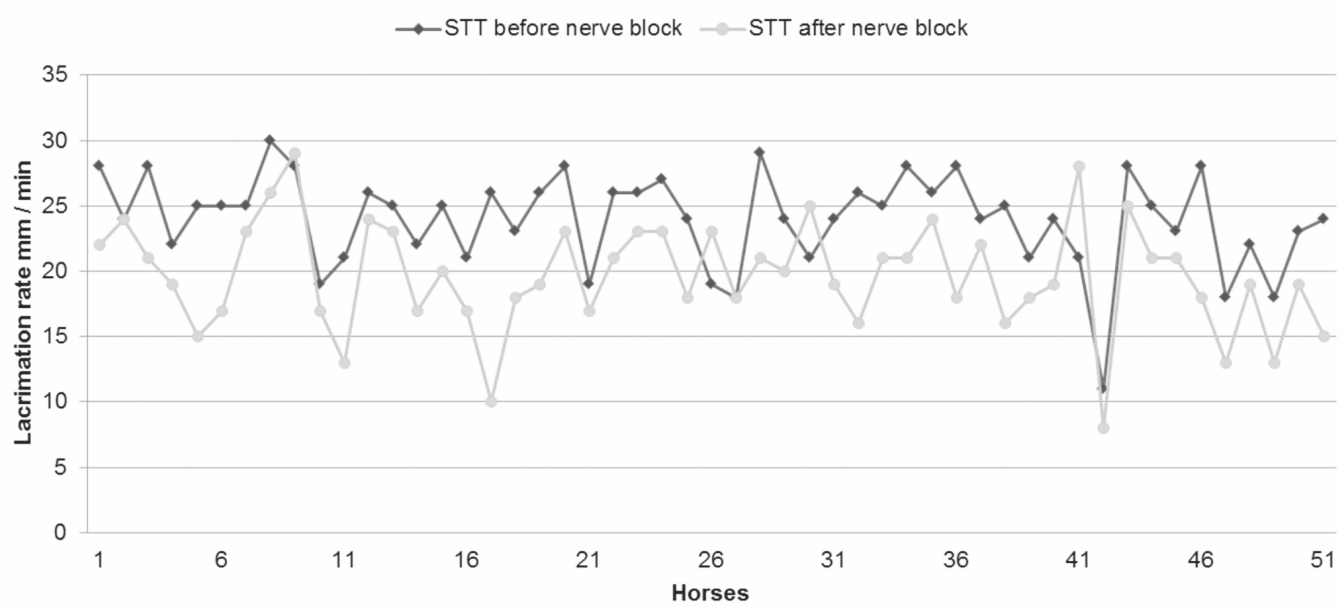

Clinical examinations

Cardiorespiratory parameters

There was no significant change in heart or respiratory rate during performance of the nerve block and during surgical procedure in both groups.

\section{Testing pain sensation}

Results were analyzed referenced to the particular group; the results were not significant.

Mechanical stimulus before and after nerve block Group 1: 40\% (16 out of 40) of the horses were tested. Group 2: $37.5 \%$ (15 out of 40) of the horses were tested.

Thermal stimulus before and after nerve block:

Group 1: 60\% (24 out of 40) of the horses were tested.

Group 2: $47.5 \%$ (19 out of 40) of the horses were tested.

The defense reactions of Group 1 compared to Group 2 are illustrated in Figure 3.
Oral extraction

The dental extraction via oral extraction, buccotomy or repulsion was successful in 78 horses. In the remaining two horses $(2.5 \%)$ the oral extraction was not possible due to the underlying pathology of the tooth. In these two horses extraction was performed under general anaesthesia at the next day.

Defense reactions

There were no significant differences in headbanging, headshaking, stepping forward and backward (Figure 4) or in amount of chewing (Figure 5) between groups.

Vocalization: There was no significant difference between Group 1 and 2.

Forty-four horses showed mild to moderate sweating (55\%) during the surgical procedure. There were no significant differences between groups.

Follow-up Examinations

Most horses showed no signs of clinical complications regar-

\section{Mechanical stimulus: reactions}

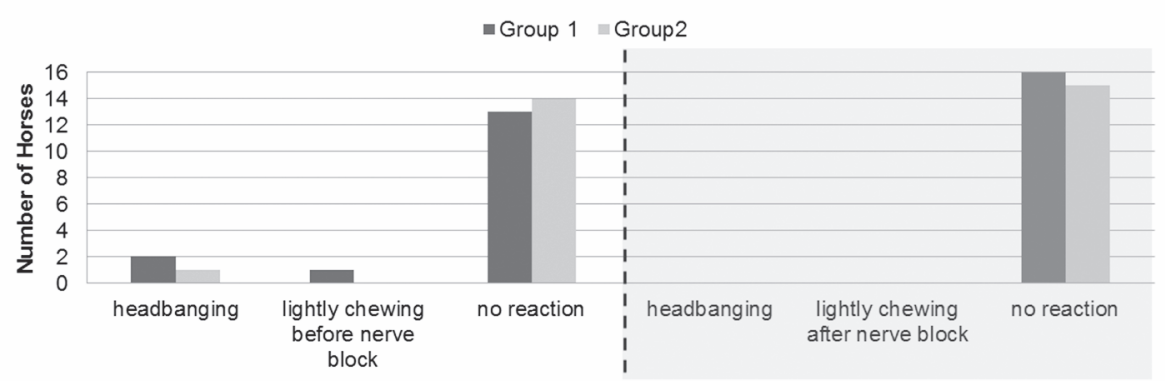

\section{Thermal stimulus: reactions}

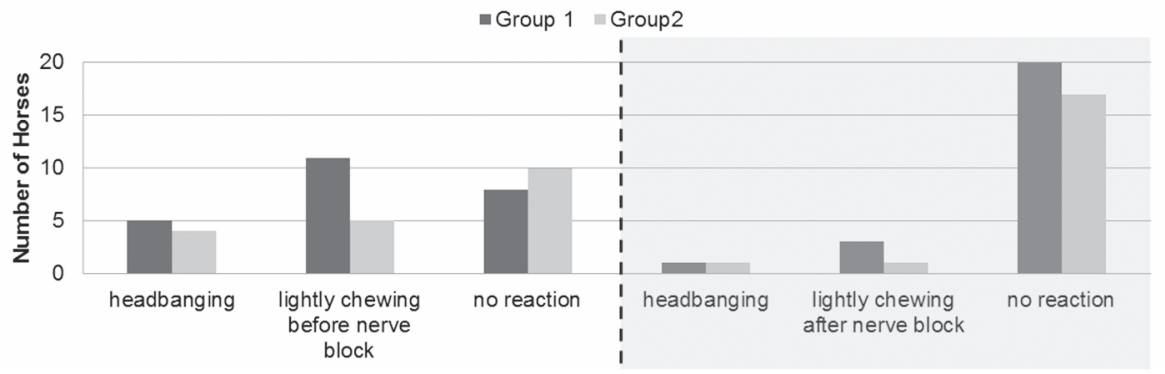

Fig. 3 Defense reactions during the mechanical and thermal stimuli before (white \& left) and after (grey \& right) maxillary nerve block (group 1: $2 \mathrm{ml} / 100 \mathrm{~kg}$ BW lidocaine and group 2: $4 \mathrm{ml} / 100 \mathrm{~kg}$ BW lidocaine) Abwehrbewegungen während der mechanischen und thermischen Stimulation vor (weiß \& links) und nach (grau \& rechts) der Lokalanästhesie des N. maxillaris (Gruppe 1: $2 \mathrm{ml}$ Lidocain $/ 100 \mathrm{~kg}$ Körpergewicht und Gruppe 2: $4 \mathrm{ml}$ Lidocain/100 kg Körpergewicht) 


\section{Defense reactions during extraction}

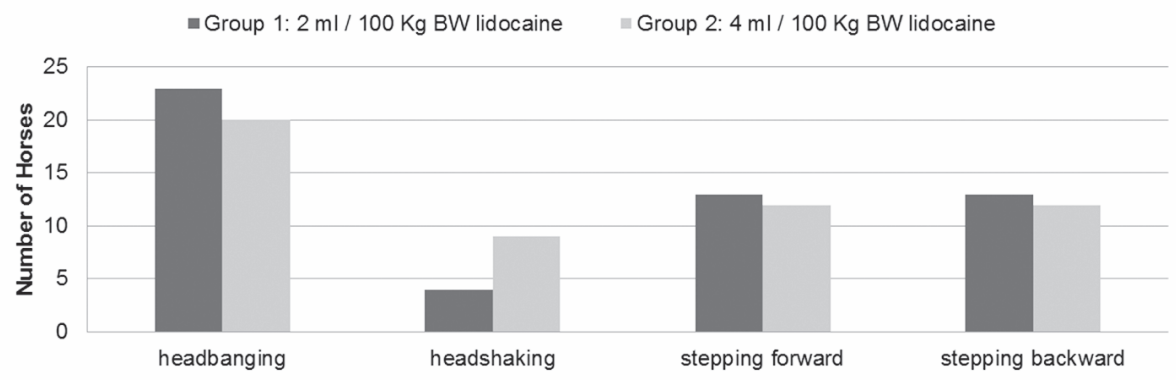

\section{Chewing during extraction}

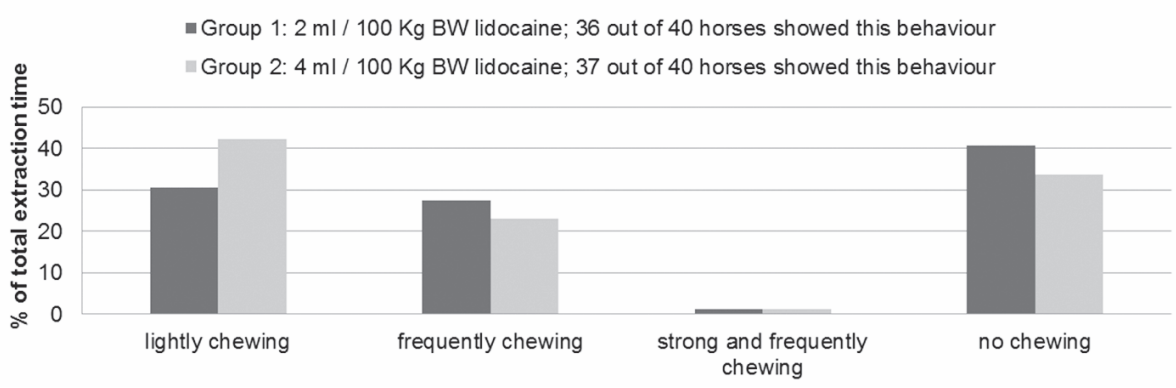

Fig. 4 Number of horses with defense reactions during extraction (group 1: $2 \mathrm{ml} / 100 \mathrm{~kg}$ BW lidocaine and group 2: $4 \mathrm{ml} / 100 \mathrm{~kg}$ BW lidocaine)

Anzahl der Pferde mit Abwehrverhalten während der Extraktion (Gruppe 1: $2 \mathrm{ml}$ Lidocain/100 kg Körpergewicht und Gruppe 2: $4 \mathrm{ml}$ Lidocain/100 kg Körpergewicht)
Fig. 5 Duration of chewing during extraction compared to total extraction time (group 1: $2 \mathrm{ml} / 100 \mathrm{~kg}$ BW lidocaine and group 2: $4 \mathrm{ml} / 100 \mathrm{~kg}$ BW lidocaine)

Daver des Kauverhaltens während der Extraktion im Vergleich zur gesamten Extraktionsdaver (Gruppe 1:2 m/ Lidocain/100 kg Körpergewicht und Gruppe 2: $4 \mathrm{ml}$ Lidocain/100 kg Körpergewicht) ding local anaesthesia after surgery. In five horses (one in group 1 and four in group 2) complications occurred:

Group 1: One horse showed a diffuse turgor ventral of the zygomatic arch; the horse did not show any signs of pain during palpating and clinical symptoms disappeared within two days without any treatment.

Group 2: Three horses with articulate swelling dorsal of the eye at the area of the supraorbital fossa developed superficial corneal ulcerations at the dependent eye. Horses were treated with antibiotic eye ointment and recovered within three weeks. One horse showed a diffuse turgor dorsal of the eye within the area of the upper palpebrae; the horse did not show any sign of pain during palpating and symptoms disappeared within two days.

\section{Discussion}

Techniques for oral tooth extraction were first described by Merillat (1906). The transoral extraction should be the first method of choice chosen by veterinarians. Although a retrograde approach to the sinus or periradicular area may be necessary to treat an existing secondary disease, oral extraction should be attempted first (Easley 2011). The possibility to perform the oral extraction in the standing horse has considerable advantages over other techniques. Despite an increased injury risk to stuff, the more comfortable position for the surgeon in front of the standing horse and the lower risk for bleeding are some advantages of sedation compared to general anaesthesia. Further risks associated with induction and recovery is lower in standing horses as well as a reduced time to complete the procedure, and reduced costs (Doherty and Valverde 2006).
Surgery in standing horses requires local anaesthesia (Day and Skarda 1991). Sufficient analgesia of the cheek teeth is necessary for advanced dental procedures performed in standing, sedated horses (Fletcher 2004). Desensitizing the maxillary branch of the trigeminal nerve is useful for surgical procedures involving the upper (cheek) teeth, paranasal sinuses, maxilla and oral cavity (Newton et al. 2000) and is achieved by local blocking the maxillary nerve within the pterygopalatine fossa (Bienert et al. 2011).

Rieder et al. (2016) verified that the maxillary nerve block performed with the EFBI-technique is a feasible clinical technique and the present study demonstrated the practicability of the EFBl-technique under clinical conditions. Only four horses required additional nose-twitch to sedation for better performance of the local nerve block. Mild reactions during needle insertion such as headshaking or stamping with a front leg appeared and were easy to handle.

Testing the analgesic effectiveness of the EFBI-technique during surgery necessitated parameters of behaviour and defense reactions of horses which could be related to pain sensation. Non-specific and specific behaviour patterns are described which are related to different conditions of pain in horses. The frequency of showing specific behaviour pattern can be used to evaluate the intensity of pain (Ashley et al. 2005). Cardiorespiratory parameters were monitored every five minutes. However, respiratory and heart rate, although often used as main indicators for pain, only have a moderate sensitivity and specificity. Using only these two parameters it is not possible to evaluate the degree of pain (Bohnet 2010). In the present clinical trial respiratory and heart rate decreased after sedation, which could be related to the depressant effect of detomidine (Tobias 2004). During setting the local nerve block and tooth extraction there was no alteration of these 
two parameters, indicating no sensation of pain or stress in our horses.

Bohnet (2010) showed that the reaction to touching the painful area, followed by pawing, head movements and kicking against the belly are sensitive, specific, and repeatable parameters for the detection of pain in horses. Regarding this, the behaviour typical for defense reactions in horses and often seen during the examination of the head (headbanging, headshaking, chewing, stepping forward, or stepping back) was used in the present study to interpret pain sensation.

Rieder et al. (2016) evaluated two methods (mechanical and thermal stimuli) for testing pain sensation of teeth and gingiva in horses. Using this experimental setup in the present study, pain sensation was tested before tooth extraction in some horses of both groups. The results showed that the mechanical stimulus did hardly cause any reactions. Furthermore, in contrast to the study of Rieder et al. (2016), the thermal stimulus resulted in less defense reactions after local anaesthesia in both groups. The larger number of horses in the present study could have influenced the results. Another reason could be that horses in our study received the opioid butorphanol in addition to detomidine. The onset of action of butorphanol in the horse is immediately after intravenous injection (Sellon et al. 2001). Therefore not only local anaesthesia, but also the analgesic effect of butorphanol may have influenced pain sensation. With the horses undergoing a maxillary cheek tooth extraction in the present study, deeper structures (e. g. the periodontal ligament) than only the gingiva and the occlusal surface of the tooth are suitable for evaluating the analgesic effect. Summarized, the results confirmed the prementioned statement of Rieder et al. (2016): General appraisement for sufficient analgesia of the maxillary cheek teeth with the two tests could not be attained. Probably there is no feasible method to verify the onset of action of the local nerve block before starting surgical intervention.

The results of the parameter chewing demonstrated that most of the horses in both groups showed either no chewing or weak to medium chewing during the surgical intervention. It is possible that the few horses showing massive chewing reacted sensitive to any kind of tangency in and around the mouth. Despite deep sedation, these horses were very nervous compared to others and probably showed this behavior independent to any painful stimulus. It is questionable whether this parameter could be related to the intensity of pain. Nevertheless, there were no significant differences between Group 1 and Group 2 showing that chewing and vocalization are specific and individual behaviour patterns that cannot be used to evaluate pain sensation during tooth extraction.

In some horses headbanging and headshaking showed similar results compared to chewing. In these rare cases it was obvious that the frequency of these two parameters increased because these horses were timid or reacted very sensitive to any kind of stimulus in and around the oral cavity. Further it must be considered that the intensity of pain-specific behaviour patterns are influenced by many factors as underlying illness, age, breed, character and temperament of the horse, earlier experiences with pain and therefore associated avoidance behaviour, and the relationship between human and animal (Bohnet 2010). But overall, headbanging and headshaking were shown mostly directed to an action during surgery (e.g. the force during inter- dental spreading). Stepping forward or back occurred only occasionally and without differences between groups, but most of the time in direct relation to the prementioned surgical intervention. Consequently, in this study the parameters "headbanging", "headshaking", "stepping forward", and "stepping back" turned out to be designative behaviour patterns when perceiving pain during dental surgery.

There were no significant differences between the horses in group 1 (2 ml/100 kg BW lidocaine) and group $2(4 \mathrm{ml} / 100 \mathrm{~kg}$ BW lidocaine) concerning the defense reactions and behaviour during the injection of the lidocaine, the complete surgical procedure or regarding the tests for pain sensation. Different data related to the required volume of lidocaine for effective maxillary nerve block in horses are published. Typical volumes recommended are ten to thirty $\mathrm{ml}$ per horse (Stephenson 2004, Dixon 2006, Tremaine 2007a). The technique to block the maxillary nerve within the pterygopalatine fossa suggested by Vlaminck and Steenhaut (2001) and by Fletcher (2004) demanded up to $20 \mathrm{ml}$ lidocaine for infiltration. The study of Staszyk et al. (2008) with cadaveric heads demonstrated that in all computed tomographic simulations the injected contrast medium surrounded the maxillary nerve in the pterygopalatine fossa independent from the insertion technique (EFBI or $\mathrm{PBI}$ ) or the volume of the contrast medium $(10 \mathrm{ml}$ or $20 \mathrm{ml})$. The results of the present study demonstrated that the smaller amount of lidocaine was sufficient to guarantee good analgesia of the maxillary cheek teeth.

Furthermore, this study showed that complications after local nerve block using a smaller volume appeared rarely compared to the larger volume. Although clinical signs for retrobulbar hematoma or other reported severe complications ranging from collapse (possibly as a result of intravascular injection of local anaesthetic) to blindness after introducing infection into retrobulbar tissues (Dixon 2006, Staszyk et al. 2008), were not seen in the present study, three horses of group 2 (large volume lidocaine) developed articulate swelling dorsal of the eye within the range of the supraorbital fossa and, as a possible result, a superficial ulcer. In two other horses of group 2 a diffuse subcutaneous swelling appeared ventral to the zygomatic arch or dorsal to the eye. A trauma to the transverse facial or maxillary vessels may result in hematoma formation causing mild to marked periocular or retrobulbar swelling, although such swelling is usually cited as being self-limiting and transient (Edwards 1930, Fletcher 2004, Gerard 2007, Tremaine 2007).

In addition, as the clinical trial of Rieder et al. (2016) already confirmed, all horses with eye related complications in the present study showed decrease lacrimation after the local nerve block. The maxillary nerve block can cause a decrease of the lacrimation fluid by anaesthetizing the lacrimal nerve (Nickel et al. 1992). A reduction in tear production has been recognized as a common cause of corneal and conjunctival lesions in both humans and animals (Gelatt 2007). The results of the Schirmer tear test demonstrated that independent from the volume of lidocaine $88.2 \%$ of the horses showed a decrease lacrimation after the nerve block. Thus, the decrease of lacrimation rate could possibly support the development of corneal ulcerations. Preventive application of eye drops or eye ointment is recommended to prevent or minimize these symptoms. 


\section{Conclusions}

The maxillary nerve block using the EFBI-technique was successful in all horses and is a highly practicable clinical method. The veterinarian should be experienced and aware of the anatomic structures of the targeted area. For the performance of the nerve block the horse has to be sedated and if necessary the head has to be fixed by a second person. Aspirating before injecting the local anaesthetic minimizes complications.

With the used pain sensation methods, there is no warranty to verify the onset of action of the local nerve block before starting oral extraction. Further tests for the evaluation of the efficacy of analgesia in maxillary cheek teeth need to be defined. Using $2 \mathrm{ml} / 100 \mathrm{~kg}$ BW lidocaine provides safe and effective regional anesthesia while extracting maxillary cheek teeth and reduces the risks of anaesthesia related complications. By reason of decrease of tear production, a preventive treatment with eye ointment is recommended.

\section{References}

Ashley F. H., Waterman-Pearson A. E., Whay H. R. (2005) Behavioral assessment of pain in horses and donkeys: application to clinical practice and future studies. Equine Vet. J. 37, 565-575

Bardell D., Iff I., Mosing M. (2010) A cadaver study comparing two approaches to perform a maxillary nerve block in the horse. Equine Vet. J. 42, 721-725

Bienert A., Rieder C., Zwick T., Feige K., Staszyk C. (2011) Maxillary Nerve Block Within the Pterygopalatine Fossa - EFBI-Technique. In: Proceedings of the American Association of Equine Practitioners Focus Meeting, Albuquerque, New Mexico, USA, 82-84

Bohnet W. (2010) Den Schmerz erkennen - Unspezifische Verhaltensweisen beim Pferd. Pferdespiegel 2, 70-74

Day T. K., Skarda R. T. (1991) The pharmacology of local anesthetics. Vet. Clin. North Am. Equine Pract. 7, 489-500

Dixon P. M., Tremaine W. H., Pickles K., Kuhns L., Hawe C., Mccann J., Mcgorum B. C., Railton D. I., Brammer S. (2000) Equine dental disease: a long term study of 400 cases. Part 4; Apical infections of cheek teeth. Equine Vet. J. 32, 182-194

Dixon P. M. (2006) Apical infections of cheek teeth and their oral extraction. In: Proceedings of the American Association of Equine Practitioners Focus Meeting, Indianapolis, Indianapolis, USA

Dixon P. M., Hawkes C., Townsend N. (2009) Complications of Equine Oral Surgery. Vet. Clin. North Am. Equine Pract. 24, 499-514

Doherty T., Valverde A. (2006) Management of sedation and anesthesia. In: Manual of Equine Anesthesia and Analgesia. Doherty, T., Valverde, A. (eds.), Blackwell Publishing Ltd., Oxford, UK, 206-259

Easley J. (1996) Equine dental development and anatomy. In: Proceedings of the American Association of Equine Practitioner, Denver, Colorado, USA, 1-19

Easley J. (2011) Equine Oral Extractions. In: Proceedings of the American Association of Equine Practitioners, Focus Meeting, Albuquerque, New Mexico, USA, 147-152

Edwards J. T. (1930) Regional anaesthesia of the head of the horse: an up to date survey. Vet. Rec. 10,973-975

Fletcher B. W. (2004) How to perform effective dental nerve blocks. In: Proceedings of the American Association of Equine Practitioners, Denver, Colorado, 233-239

Ford T. S. (1991) Standing Surgery and Procedures of the Head. Vet. Clin. North Am. Equine Pract. 7, 583-603

Gaynor J. S., Hubbell A. E. (1991) Perineural and spinal anesthesia. Vet. Clin. North Am. Equine Pract. 7, 501-519

Gelatt K. N. (2007) Ophthalmic Examinations and Diagnostics. In: Veterinary Ophtalmology (4th edn). Gelatt KN (ed). Blackwell Publisher, Oxford, UK, 462-463
Gerard M. (2007) Regional anesthesia techniques for the equine head. In: Proceedings of the North American Veterinary Conference, Orlando, Florida, USA

Lowder M. Q. (1999) How to Perform Oral Extraction of Equine Cheek Teeth. In: Proceedings of the American Association of Equine Practitioners, Albuquerque, New Mexico, USA

MacDonald M. H., Basile T., Wilson W. D., Puchalski S. M., Scheuch B. C. (2006) Removal of Maxillary Tooth Fragments and Root Remnants in Standing Horses. In: Proceedings of the American Association of Equine Practitioners, Focus Meeting, Indianapolis, USA

Merillat M. A. (1906) Tooth removal. In: Equine Dentistry and Diseases of the Mouth. Vet. Surg., 1, Alex Eber, Chicago, USA

Moyer W., Schumacher J., Schumacher J. (2011) Regional Anesthesia: Nerve blocks of the head. In: Equine Joint Injection and Regional Anesthesia. 4. Ed., W. Moyer, J. Schumacher, J. Schumacher (eds.) Acad. Vet. 120-121

Newton S. A., Knottenbelt D. C., Eldrige P. R. (2000) Headshaking in horses: possible aetiopathogenesis suggested by the results of diagnostic tests and several treatment regimes used in 20 cases. Equine Vet. J. 32, 208-216

Nickel R., Schummer A., Seiferle E. (1992) Lehrbuch der Anatomie der Haustiere. Band IV: Nervensystem, Sinnesorgane, Endokrine Drüsen. Parey, Berlin und Hamburg, Germany, 307-308

Prichard M. A., Hackett R. P., Hollis N. (1992) Long term outcome of tooth repulsion in horses; A retrospective study of 61 cases. Vet. Surg., 21, 145-149

Rawlinson J. E. (2011) Adressing Pain: Regional Nerve Blocks. In: American Association of Equine Practitioners, Focus Meeting, Albuquerque, New Mexico, USA, 74-81

Rieder C. M., Staszyk C., Hopster K., Feige K., Bienert-Zeit A. (2016) Maxillary nerve block within the equine pterygopalatine fossa with different volumes: practicability, efficacy and side-effects. Pferdeheilkunde 32, 132-140

Rubin A. P. (1995) Complications of local anaesthesia for ophthalmic surgery. Briti. J. Anaesth. 75, 93-96

Sellon D. C., Monroe V. L., Roberts M. C., Papich M. G. (2001) Pharmacokinetics and adverse effects of butorphanol administered by single intravenous injection or continuous intravenous infusion in horses. Am. J. Vet. Res. 62 (2), 183-189

Staszyk C., Bienert A., Bäumer W., Feige K., Gasse H. (2008) Simulation of local anaesthetic nerve block of the maxillary nerve within the pterygopalatine fossa: Anatomical landmarks defined by computed tomography. Res. Vet. Sci. 85, 399-406

Stephenson R. (2004) Oral extraction of equine cheek teeth. UK. Vet. 9, $11-17$

Tobias S. (2004) Untersuchung zur Pharmakokinetik des Arzneistoffes Detomidin hinsichtlich der Dopingrelevanz beim Pferd. Institute for Pharmacology, Toxicology, and Pharmacy, University of Veterinary Medicine Hannover, Foundation, doctoral thesis

Tremaine W. H. (2007a) Local analgesic techniques for the equine head. Equine Vet. Educ. 19, 495-503

Tremaine W. H. (2007b) Zahnextraktion. In: Zahnheilkunde in der Pferdepraxis. 2th ed. Baker, G.J., Easley, J. (eds), Elsevier GmbH, Munich, Germany, 287-317

Vlaminck L., Steenhaut M. (2001) Extractie van de maaltanden bij het paard. Vlaams Dierg. Tijdsch. 70, 337-343

Erweiterte Zusammenfassung Anästhesie des N. maxillaris in der Fossa pterygopalati-
na zur Extraktion maxillärer Backenzähne bei 80 Pferden

Die Anästhesie des N. maxillaris in der Fossa pterygopalatina wurde bereits in vorangegangenen Studien auf Durchführbarkeit, Wirksamkeit und Risiken untersucht. Die Anästhesie des N. maxillaris mittels der Extraperiorbitalen Fettkörper Technik (EFBI) soll eine Anästhesie der maxillären Backenzähne mit einem verringerten Risiko für Komplikationen gewährleisten. 
Um diese These zu bestätigen sind weitere klinische Erhebungen notwendig. Die vorliegende Arbeit zielte zum einen darauf ab, die Praktikabilität der EFBI-Technik an einer größeren Anzahl von Pferden in der täglichen Praxis zu erproben. An den Tieren wurde nach vorangegangener Diagnose- und Indikationsstellung die Extraktion eines maxillären Backenzahnes unter Sedierung vorgenommen. Zum anderen sollten mögliche Risiken und Komplikationen, die diese Form der Leitungsanästhesie bergen kann, unter realen klinischen Bedingungen erfasst werden. Des Weiteren sollte der anästhetische Effekt, der durch die EFBI-Technik erreicht wird, evaluiert werden und ein möglicher Unterschied der Wirksamkeit bei Verwendung zweier verschiedener Mengen des Lokalanästhetikums untersucht werden.

In diese verblindete, randomisierte und prospektive Studie wurden achtzig Pferde aufgenommen. Die Tiere wiesen unterschiedliche Alter, Rassen und Geschlechter auf und wurden alle für eine unilaterale, maxilläre Backenzahnextraktion vorstellig. Die Pferde wurden mithilfe einer fortlaufend nummerierten Liste vorab in zwei Gruppen zu je vierzig Pferden aufgeteilt und erhielten entweder $2 \mathrm{ml} / 100 \mathrm{~kg}$ Körpergewicht Lidocain (Gruppe 1) oder $4 \mathrm{ml} / 100 \mathrm{~kg}$ Körpergewicht Lidocain (Gruppe 2). Die Anästhesie des N. maxillaris wurde mittels EFBI-Technik nach Staszyk et al. (2008) vorgenommen. Abwehrbewegungen der Pferde und Nebenwirkungen während und im Anschluss an die Anästhesie wurden dokumentiert. Bei 51/80 Pferden wurde fünf Minuten vor und nach der Leitungsanästhesie ein Schirmer Tränentest zur Messung der Tränenflüssigkeitsproduktion am Auge der anästhesierten Seite durchgeführt. Zu diesen beiden Zeitpunkten testete der verblindete Untersucher ebenfalls die Schmerzausschaltung an den Zähnen und der umliegenden Gingiva durch mechanische und thermische Stimuli nach dem Vorgehen von Rieder et al. (2016). Während der Tests wurden Abwehrreaktionen der Pferde dokumentiert. Die anschließende orale Extraktion des maxillären Backenzahnes wurde nach Lowder (1999) durchgeführt. Misslang die orale Extraktion wurde der Zahn mittels minimalinvasiver Bukkotomie oder Expulsion via Steinmann-Pin entfernt. Kardiorespiratorische Parameter (Herz- und Atemfrequenz), Abwehrreaktionen der Pferde (Kopfschlagen, Kopfschütteln, Vor- und Zurücktreten), Schwitzen, Reaktionen der Pupillen, Leerkauen und LautäuBerungen vor und während des operativen Eingriffs wurden alle fünf Minuten dokumentiert. Die ersten vier Tage nach der Extraktion wurden täglich klinische Untersuchungen mit besonderem Augenmerk auf Schwellungen oder sekundäre Blutungen im Injektionsbereich vorgenommen. Der okuläre Bereich wurde auf Blepharospasmus, Miosis oder geschwollene Lider hin kontrolliert. In der vorliegenden Studie konnte die Leitungsanästhesie des N. maxillaris bei 74 von 80 Pferden im ersten Versuch durchgeführt werden. Vier Pferde benötigten zusätzlich das Anlegen einer Nasenbremse und bei zwei Pferden musste die Injektionskanüle neu platziert werden. Kein Abwehrverhalten während der Anästhesie zeigten 65 der 80 Pferde; die verbliebenen 15 zeigten moderate Abwehrreaktionen. Bei ebenfalls 65 Pferden wurden keine Komplikationen durch die Leitungsanästhesie vermerkt.
Ohne einen feststellbaren signifikanten Unterschied zwischen Gruppe 1 (geringere Menge Lidocain) und Gruppe 2 (größere Menge Lidocain) war bei 13 der verbliebenen Pferde eine Reposition der Injektionskanüle nach Blutaspiration notwendig, bei zwei Tieren trat eine diffuse Schwellung im Injektionsbereich auf.

Die Ergebnisse des Schirmer Tränen Tests zeigten keinen signifikanten Unterschied hinsichtlich des Tränenflusses auf, obwohl eine Tendenz zur Abnahme des Tränenflusses nach der Leitungsanästhesie zu erkennen war. In beiden Gruppen war außerdem bei einigen Pferden eine geringgradige Mydriasis nach der Leitungsanästhesie zu beobachten, die jedoch bei fast allen Tieren bis zum Ende des Eingriffs wieder verschwunden war. Des Weiteren wurde in beiden Gruppen kein signifikanter Unterschied der Herz- und Atemfrequenz während der Leitungsanästhesie und des operativen Eingriffs festgestellt. Die Ergebnisse der Überprüfung der Schmerzausschaltung mittels thermischem und mechanischem Reiz zeigten keinen signifikanten Unterschied zwischen den Gruppen. Die Abwehrbewegungen der Pferde während der Operation wiesen keinen signifikanten Unterschied zwischen beiden Gruppen auf. Eine Extraktion des Zahnes mittels oraler Extraktion, minimalinvasiver Bukkotomie oder via Steinmann-Pin gelang bei 78 der Pferde. Bei den verbliebenen beiden Tieren wurde der Zahn am darauffolgenden Tag unter Allgemeinanästhesie entnommen. Postoperationem traten bei fünf Pferde geringgradige Komplikationen auf, die mit der Leitungsanästhesie des $\mathrm{N}$. maxillaris in Zusammenhang gebracht werden konnten. Hierbei handelte es sich fast ausschließlich um Schwellungen im Bereich der Augenpartie oder oberflächliche Hornhautulzerationen auf der anästhesierten Seite. Pferde aus Gruppe 2 mit der größeren Menge Lidocain zeigten diese Symptome signifikant häufiger. Nach symptomatischer Behandlung mit Augensalben (lokal) und Antibiotika (systemisch) verschwanden die Symptome spätestens nach drei Wochen bei allen Tieren.

Die Anästhesie des N. maxillaris mittels der EFBI-Technik gelang bei allen Pferden und ist als gut durchführbare und erfolgreiche Methode für die tägliche Klinik anzusehen. Der Tierarzt sollte jedoch genave Kenntnisse der anatomischen Strukturen des betreffenden Areals besitzen. Das Pferd sollte für die Leitungsanästhesie sediert sein und von einer zweiten Person am Kopf fixiert werden. Vor der Injektion des Lokalanästhetikums sollte aspiriert werden um mögliche Komplikationen zu minimieren. Die durchgeführten Tests zur Überprüfung der Schmerzausschaltung vor der Operation geben keine Garantie des Wirkungseintritts der Leitungsanästhesie. Für die Evaluierung der wirksamen Analgesie im maxillären Backenzahnbereich sind weitere Tests nötig. Die Verwendung von $2 \mathrm{ml} / 100 \mathrm{~kg}$ Körpergewicht Lidocain ist ausreichend für die Extraktion maxillärer Bakkenzähne und reduziert die Risiken von Komplikationen durch die Leitungsanästhesie. Aufgrund der Abnahme der Tränenflüssigkeitsproduktion sollten präventiv Augensalben appliziert werden um die Hornhaut feucht zu halten.

Schlüsselwörter: Pferd, Pferdezahnheilkunde, Leitungsanästhesie, Anästhesie N. maxillaris, EFBI-Technik, Zahnextraktion 